\title{
A clarion call to South African Radiology
}

Bob Bury, the editor of Clinical Radiology, has kindly written an accompanying editorial for this issue of the South African Journal of Radiology. To place his piece in context, one has to at least have paged through the special June 2010 edition of Clinical Radiology on molecular imaging (MI). ${ }^{1}$ The introductory article explains the role of small molecules in the form of peptides or antibodies that are linked to an imaging label and are destined to attach to a tumour antigen. In the case of PET and SPECT, the labels are radioactive substances. RSSA President Clive Sperryn's thoughts on MI appear in this SAJR's Radioactive News section.

New in the field is optical MI. Fluorescent dyes are important, but the recent introduction of quantum dots, carbon nanotubes and gold nanoshells defines the scale of magnitude being referred to. Acoustic MI has seen the introduction of micro- or nanoparticles in the form of microbubbles, perfluorocarbon nanodroplets and liposomes. MRI labels include paramagnetic iron oxide and manganese oxide.

Where does the radiologist stand relative to all this? I do not know, and feel like Moses of Old 'on the outside, looking in'. What I do know is that we need to define our role and define it fast. We need to ask many questions. For one: Are we properly prepared for these changes that loom on our doorstep? This is probably the most pertinent question needing a response. I believe that our primary examinations fall short, with a lack of knowledge of physiological and patho-physiological principles seeming to represent the most significant hiatus. I echo Bob Bury's words as a clarion call to South African Radiology:

'... if we want to continue to attract the brightest and best of our young doctors into the specialty, we need to pick up the new techniques and run with them. If we don't do it, and do it well, someone else will.'

\section{Jan Lotz}

Editor-in-Chief

1. Clin Radiol 2010; 65:499-582.
I was delighted and flattered when Jan Lotz invited me to contribute to the South African Journal of Radiology; although, if you were aware of how little I know about molecular imaging (MI - yet another acronym to confuse with MR), you might reasonably be wondering why on earth he approached me. Well, I edit Clinical Radiology, the journal of the Royal College of Radiologists, and we recently published a special issue ${ }^{1}$ on this hot topic. I wrote a brief editorial introducing the issue, then sat back to marvel as the contributions from around the world came in, and Jan asked if I would write a similar piece for the SAJR. I'll resist the temptation to reference each paper in our special issue in a blatant attempt to boost the journal's impact factor, but hopefully most of you will have electronic access to it through your institutions or possibly as Fellows of the College.

When you are as close to retirement as I am, it can get a bit depressing to find your hard-won skills becoming obsolete (remember lymphangiography, anyone?), and to see your juniors effortlessly overtaking you in the application of new imaging technology. The great thing about MI is that most radiologists - even those irritatingly bright young ones - are nearly as ignorant of the subject as me. In fact, of course, it transpires that most of us have practised some aspects of MI, often without realising it. My sub-specialty is nuclear medicine, or radionuclide imaging (RNI) as we are now required to call it, in the UK at least. RNI practitioners have always boasted, quite rightly, that

\section{Molecular imaging}

it is a functional imaging technique, so it is not surprising that many of the early developments in MI have come in this field, in particular those utilising positron emission tomography (PET). Similarly, anyone who has bought an MR machine recently will no doubt have tentatively pressed the DWI button to see what it does, and functional MR is already an accepted imaging technique in the fields of neurology and cardiology. However, MI is much more than an extra option on the MR console, or a sexed-up version of the bone scan.

MI has been defined as the ability to visualise and quantitatively measure the function of biological and cellular processes in vivo. ${ }^{2}$ Whereas 20 years ago that definition would probably, with few exceptions, only have applied to RNI techniques, it now encompasses all imaging modalities except plain film, and includes some, such as optical imaging, that are completely unfamiliar to most of us. Even ultrasound, that most anatomical of techniques, is now utilising molecularly targeted micro-bubbles to take diagnosis to the cellular level, and similar bubbles can be used to deliver tailored therapy agents to tumour tissue by using the ultrasound beam to disrupt them in situ. Computed tomography also has some MI applicability, with dynamic contrast enhancement techniques being used to look at processes such as tumour angiogenesis and tissue hypoxia. And, of course, the development of new molecular targets for novel PET agents is a wellestablished growth area in MI research. And there's still more: I could 
go on to talk, at least superficially, about optical and photo-acoustic imaging and Raman spectroscopy/microscopy, but I probably wouldn't be able to fool you for very long. So, it is likely that all radiologists will need to learn new applications for their imaging modalities of choice, in addition to mastering a number of completely new techniques.

In addition to these obvious imaging aspects, the other issue I want to mention in relation to $\mathrm{MI}$ is the political/service delivery dimension. I don't know how much of a problem so-called turf wars have been in South African medicine, but in the UK we have always thought of these battles for the possession of areas of practice (and income) as a feature of the North American, insurance-funded, medical scene. Lately, though, we have realised that the state-funded NHS is not immune. For example, we have already lost much of cardiac imaging to the cardiologists - not just the invasive coronary angiography and intervention, but also a lot of the cardiac MR work; and in mainland Europe, the usurpation of imaging techniques by clinicians has been even more widespread. MI is a new and exciting field, with applications in therapy as well as diagnosis, and there's no doubt that some clinicians will want to get what they see as their share of the action. I suppose it doesn't matter to the patient which specialist undertakes their investigation, as long as they do it well, but in the main these are imaging investigations we are talking about, and radiologists are the imaging experts. I also believe that if we want to continue to attract the brightest and best of our young doctors into the specialty, we need to pick up the new techniques and run with them. If we don't do it, and do it well, someone else will.

When you read a paper in a journal of clinical radiology which includes a section headed 'Molecular imaging of the metabolome: hypoxia-inducible factor (HIF) and the Warburg effect,', you realise that times are changing, and that we have moved beyond the demonstration of gross anatomy (although that's clearly still important) into a world where we can reveal cellular physiology and pathophysiology on a scale that is several orders of magnitude smaller than anything we have been used to. In fact, now that I think about it, this exciting new direction for radiology is almost enough to make me wish I wasn't retiring at the end of the year ... almost.

And that's it, really. It's all very well me exhorting you to take on this new area of practice - I'm at the end of my career, and won't need to do any of the work myself. However, I am about to become a net consumer of healthcare for the first time in my adult life, so I may soon have a very direct vested interest in the competence and skill set of the next generation of radiologists! I should also say at this point that, having visited your wonderful country for the first time a couple of years ago and fallen in love with it, I shall be available from the end of 2010 for expenses-paid lecturing tours of the wine-producing areas of SA, preferably during your summer months. Just don't ask me to lecture on MI.

1. Clin Radiol 2010;65:499-582.

2. Mankoff DA. A definition of molecular imaging, J Nucl Med 2007;48(6):18N-21N

3. Gillies RJ, Anderson AR, Gatenby AR, Morse DL. The biology underlying molecular imaging in oncology: from genome to anatome and back again. Clin Radiol 2010; 65:517-521.

Bob Bury

Editor-in-Chief

Clinical Radiology

\section{SAJR bigger and quicker}

The South African Journal of Radiology has, under the excellent leadership of Jan Lotz, exceeded all expectations and is growing exponentially, with the development of a backlog of accepted manuscripts awaiting publication. We are pleased to announce that, through generous sponsorship by Philips Medical Systems via an ongoing commitment to the RSSA CPD programme, the size of the journal has been increased. The increase in page count will facilitate a reduction in the waiting time to publication. The increased capacity of the $S A J R$ assumes additional significance in the light of new requirements for the registration of specialists in South Africa. The most significant point is the appointment of the Colleges of Medicine of South Africa (CMSA) as the executor of a single exit exam for all registrars entering from 1 January 2011 and the requirement of completion of a research component for registration as specialists. The RSSA's contribution through the SAJR to produce a number of bumper issues will allow increased MMed publications.

Clive Sperryn

President, RSSA 